\title{
Temperature dependence of species concentrations near the substrate during diamond chemical vapor deposition
}

\author{
E. J. Corat ${ }^{2)}$ and D. G. Goodwin \\ Division of Engineering and Applied Science, California Institute of Technology, Pasadena, \\ California 91125
}

(Received 3 August 1992; accepted for publication 9 April 1993)

\begin{abstract}
Measurements have been made of the temperature dependence of $\mathrm{CH}_{3}, \mathrm{CH}_{4}$, and $\mathrm{C}_{2} \mathrm{H}_{2}$ very near the substrate during filament-assisted diamond growth. $\mathrm{CH}_{3}$ was detected using $(2+1)$ resonance-enhanced multiphoton ionization (REMPI), and $\mathrm{CH}_{4}$ and $\mathrm{C}_{2} \mathrm{H}_{2}$ concentrations were measured using sampling mass spectrometry. A strong dependence of the $\mathrm{CH}_{3} \mathrm{REMPI}$ signal on substrate temperature was observed, which at low temperatures may be characterized as having an activation energy of approximately $4 \pm 1 \mathrm{kcal} / \mathrm{mole}$. Methane and acetylene, on the other hand, are relatively independent of substrate temperature. These results are most likely due to recombination of methyl to methane or ethane in the cool gas layer near the substrate or on the surface at low substrate temperatures.
\end{abstract}

\section{INTRODUCTION}

The technology of diamond film deposition has developed rapidly since the discovery that diamond could be grown efficiently under metastable conditions by chemical vapor deposition (CVD). Polycrystalline films can now be produced with optical, mechanical, and thermal properties approaching those of natural diamond. Nevertheless, many proposed applications for diamond require that several remaining problems be overcome, for example, the high growth temperatures needed, the incorporation of hydrogen and $\mathrm{sp}^{2}$ carbon impurities, and the relatively low efficiency (and therefore high cost) of current growth processes.

One barrier to overcoming these problems is that the fundamental mechanisms of diamond growth and graphite suppression under CVD conditions are not well understood. Recent work in several laboratories has shown that the methyl radical $\mathrm{CH}_{3}$ is the dominant growth species under typical conditions, ${ }^{1-5}$ but under some conditions diamond can grow from acetylene as well. ${ }^{4}$ It has also been proposed that atomic carbon may contribute to diamond growth in some plasma environments. ${ }^{6,7}$ Mechanisms have been proposed for incorporation of carbon into the diamond lattice from either methyl $1^{8-12}$ or acetylene. ${ }^{12-15}$

One important test of a growth mechanism is whether it can reproduce the observed dependence of the growth rate on substrate temperature. ${ }^{16,17}$ The measured temperature dependence, however, may have two sources: the intrinsic temperature dependence of the surface growth mechanism, and the variation with substrate temperature of the gas-phase reactants (e.g., $\mathrm{CH}_{3}, \mathrm{C}_{2} \mathrm{H}_{2}, \mathrm{H}$ ) at the surface. To compare theory with experiment, it is first necessary to measure the dependence of the gas-phase reactant concentrations at the surface on substrate temperature. This information is also useful for validating computational models of the diamond growth environment. ${ }^{7,18-22}$

\footnotetext{
a) Permanent address: Instituto Nacional de Pesquisas Espaciais, Săo José dos Campos, SP, Brazil.
}

In this paper, we examine the effect of substrate temperature on the gas-phase concentrations of $\mathrm{CH}_{3}, \mathrm{CH}_{4}$, and $\mathrm{C}_{2} \mathrm{H}_{2}$ very close to the substrate during filamentassisted diamond growth. The methyl radical is detected in situ using resonance-enhanced multiphoton ionization (REMPI), which has been shown previously to be a sensitive diagnostic for methyl under filament-assisted diamond growth conditions. ${ }^{23}$ Methane and acetylene are measured by sampling mass spectrometry.

The results of this study show that the $\mathrm{CH}_{3}$ concentration near the substrate is significantly depleted at substrate temperatures below $1000 \mathrm{~K}$. The $\mathrm{CH}_{4}$ and $\mathrm{C}_{2} \mathrm{H}_{2}$ concentrations near the substrate are only weakly dependent on substrate temperature. As discussed below, the most likely explanation for these results is either homogeneous recombination of methyl to form methane or ethane occurring in the cool gas region near the substrate, or heterogeneous recombination on the diamond surface. However, surface reactions which produce $\mathrm{CH}_{3}$ (particularly etching of $\mathrm{sp}^{2}$ carbon by atomic hydrogen) may contribute as well to the observed temperature dependence.

\section{EXPERIMENTAL}

The experimental apparatus is shown schematically in Fig. 1. The hot filament reactor consists of a $2.0 \mathrm{inch}$ od five-way cross with water-cooled walls. The gas inlet and the electrical feedthroughs for the filament current and the ionization probe bias are in the top arm of the cross, and the electrical feedthrough for the substrate temperature control and the gas exhaust to the vacuum pump are in the bottom arm. A tee in the exhaust line diverts a small portion of the exhaust to a quadrupole mass spectrometer for on-line analysis during the REMPI measurements. Two opposing side arms are fitted with calcium fluoride windows to allow the laser beam inside the reactor.

Figure 1(b) shows the filament, substrate and ionization probe geometry in more detail. The substrate consists of a $5 \mathrm{~mm}$ wide, $20 \mathrm{~mm}$ long, and $125 \mu \mathrm{m}$ thick molybdenum foil. The substrate is heated electrically using a dc 

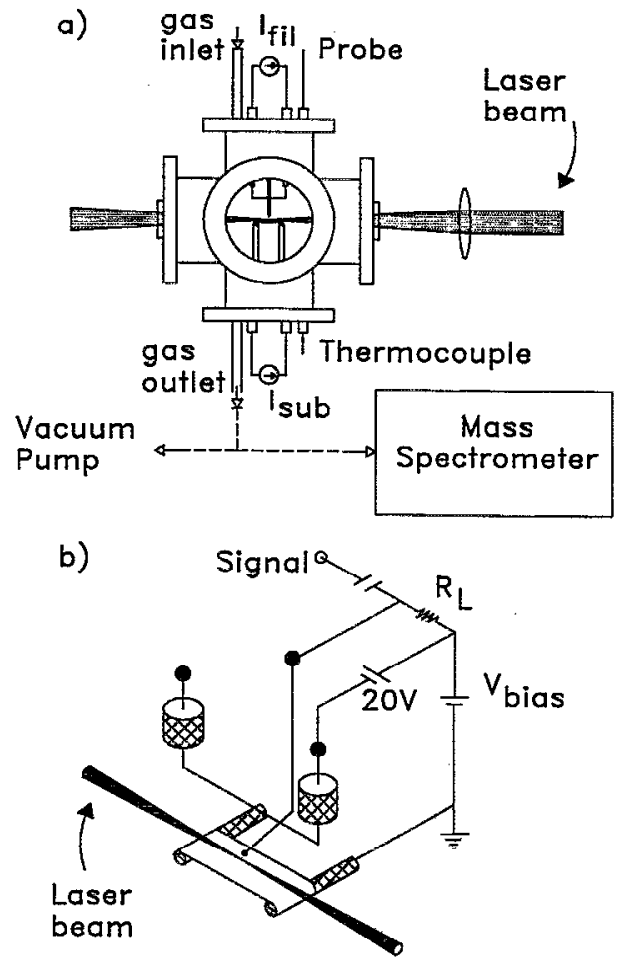

FIG. 1. (a) Schematic of experimental setup. (b) Close-up showing filament, substrate, ionization probe, laser beam, and biasing scheme.

current, which allows us to control its temperature independently of the filament temperature. The substrate temperature is measured with an icepoint-corrected chromelalumel thermocouple (type $\mathrm{K}$ ) spot-welded to the center of the substrate lower surface. The substrate is supported by two $1.6 \mathrm{~mm}$ diameter tungsten posts, which are in turn mounted on a water-cooled copper feedthrough.

The filament consists of a single, straight $200 \mu \mathrm{m}$ diameter tungsten wire, approximately $25 \mathrm{~mm}$ long, and was typically kept at a distance of 7 to $15 \mathrm{~mm}$ from the substrate. The lowest attainable substrate temperature (with no power applied) was $900 \mathrm{~K}$ at $7 \mathrm{~mm}$ and $700 \mathrm{~K}$ at 15 $\mathrm{mm}$, when the filament temperature was kept at $2200 \mathrm{~K}$.

The filament brightness temperature is measured through a glass viewport on a side arm using a one-color disappearing-filament pyrometer. While we report here only the directly-measured brightness temperature, an emissivity correction can be applied to estimate the true filament temperature. ${ }^{24}$

The ionization probe is a $250 \mu \mathrm{m}$ platinum wire supported by a ceramic tube. A bead was formed on the probe end by a standard arc thermocouple welder. The probe bead is located $2 \mathrm{~mm}$ above the center of the substrate. The laser is focused just above the substrate, at a distance from the substrate of less than $0.5 \mathrm{~mm}$. Since modeling studies ${ }^{18}$ have shown that the chemical mean free path of $\mathrm{CH}_{3}$ is approximately $1 \mathrm{~mm}$ under filament-assisted conditions, we expect the methyl concentration at the measurement position to be essentially the same as that at the film sur- face. Either a 20 or $50 \mathrm{~cm}$ focal length focusing lens is used, resulting in a beam waist of less than $40 \mu \mathrm{m}$.

To make the $\mathrm{CH}_{4}$ and $\mathrm{C}_{2} \mathrm{H}_{2}$ measurements, the experimental setup was modified to accommodate a quartz microprobe for mass spectroscopic sampling. In the present apparatus it was not possible to accommodate both the microprobe and the ionization probe simultaneously, and so $\mathrm{CH}_{4}$ and $\mathrm{C}_{2} \mathrm{H}_{2}$ concentrations were measured with the microprobe in separate experiments which replicated the conditions of the REMPI $\mathrm{CH}_{3}$ measurements. To insure that the conditions were identical, the gas exhaust composition was measured both during the REMPI and microprobe experiments, and used as a check that the conditions were the same. We found that changes in the gas composition at the substrate, as measured with the microprobe, were always reflected in the exhaust gas also, even though the measured absolute mole fractions were different.

The microprobe is a $6 \mathrm{~mm}$ diameter quartz tube, drawn down to a probe tip diameter of $150 \mu \mathrm{m}$. The pressure inside the probe is held at 0.3 Torr, to quench chemistry other than radical recombination. This sampling method has been used successfully by Harris, Weiner and Perry under similar conditions. ${ }^{25}$ The sampled gas flows past an orifice, which allows a small portion of the gas into the quadrupole mass spectrometer ionizer. Methane and acetylene are monitored from mass peaks 15 and 26, respectively. A calibration gas mixture of $0.3 \% \mathrm{CH}_{4}$ and $0.3 \% \mathrm{C}_{2} \mathrm{H}_{2}$ in $\mathrm{H}_{2}$ was used to calibrate the signal to yield absolute mole fractions.

The UV beam used for the REMPI measurements was produced by frequency-doubling the output of a YAGpumped pulsed dye laser (Continuum YG 661 pumping a TDL 51) in an autotracking converter (INRAD). The dye used was DCM, dissolved in DMSO to extend its emission to $670 \mathrm{~nm}$. The dye laser linewidth is approximately 0.08 $\mathrm{cm}^{-1}$. After frequency doubling, a pulse energy of $1 \mathrm{~mJ}$ with a typical duration of 7-8 $\mathrm{ns}$ was obtained at the wavelength of the $\mathrm{CH}_{3}$ REMPI line $(333.5 \mathrm{~nm})$.

The REMPI signal from the ionization probe was amplified and detected by a boxcar averager (Stanford Research Systems SR 250), using an integration gate width of 100 ns. The signal was then digitized and sent to a microcomputer for further processing.

Before any measurements were taken, the substrate was scratched with diamond paste and a diamond film was grown for at least 12 hours, using a gas flow of $100 \mathrm{sccm}$ of $0.5 \%$ methane in hydrogen, a filament brightness temperature of $2200 \mathrm{~K}$, and a substrate temperature of $1000 \mathrm{~K}$. Under these conditions, a continuous diamond film with typical crystal size of approximately $1 \mu \mathrm{m}$ was always observed to grow.

All results presented here were obtained for a pressure of 35 mbar.

\section{VALIDATION OF REMPI DETECTION SCHEME}

A typical survey ionization spectrum is shown in Fig. 2. This spectrum was taken immediately above the substrate, using a gas mixture of $0.5 \% \mathrm{CH}_{4}$ in $\mathrm{H}_{2}$. The main features in this spectrum are the $\mathrm{CH}_{3}(2+1)$ REMPI 


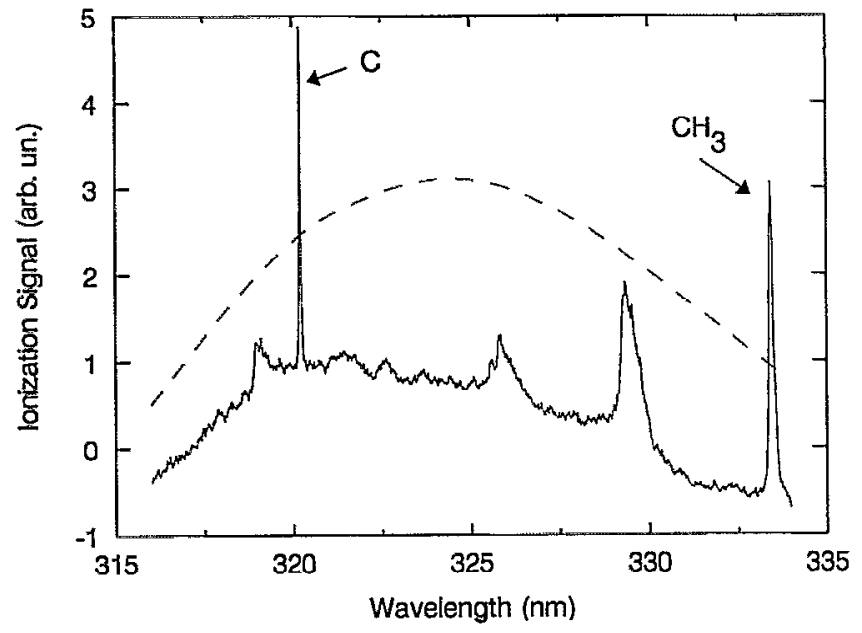

FIG. 2. Typical survey ionization spectrum. Dashed line shows laser energy variation.

signal at $333.5 \mathrm{~nm}$ and the atomic carbon $(2+1)$ REMPI signal at $320.2 \mathrm{~nm}$, which results from photolytically produced $\mathrm{C}$. We were not able to identify the broad peak near $326 \mathrm{~nm}$. Another feature is the high background ionization level, which is a function of laser energy. The two broad peaks near 319 and $329 \mathrm{~nm}$ are close to $\mathrm{CH}_{3}$ assignments. Celii et al. ${ }^{23}$ observed, however, that the $\mathrm{CH}_{3} 3 p^{2} A_{2}^{\prime \prime} 2_{1}^{1}$ transition is hidden under an unassigned peak at $329.1 \mathrm{~nm}$. We did not observe the other unattributed peak at 332.1 nm observed by Celii et al., even at the highest filament temperatures in our system.

The peak at $333.5 \mathrm{~nm}$ results from the vibrationless (0-0) two-photon absorption from the $X^{2} A_{2}^{\prime \prime}$ electronic ground state of $\mathrm{CH}_{3}$ to the $3 p^{2} A_{2}^{\prime \prime}$ Rydberg state, followed by an incoherent single-photon ionization. The observed peak is the strong $Q$ branch of the band, whose rotational structure is completely unresolved, due to the effect of predissociation on the rotational linewidth.

All results reported below are obtained from the peak of this transition, correcting for background ionization. To relate this signal to the $\mathrm{CH}_{3}$ concentration, several factors must be considered: (1) the electron collection must be saturated, (2) the collection efficiency must be independent of changes in parameters to be varied (i.e., temperature), and (3) the Boltzmann distribution of population among the vibrational and rotational levels of the lower electronic state must be accounted for.

Obtaining saturated electron collection depends primarily on shaping the electric field near the probe appropriately. The biasing scheme used in these measurements is shown in Fig. 1(b). The substrate is grounded and the probe and filament are positively biased. The filament bias was maintained at $20 \mathrm{~V}$ less than the probe bias. The electrical noise due to thermionic electron emission was filtered when the filament biasing power supply was used. Its output shunt capacitance was found to substantially reduce the thermionic emission noise, and no further shielding of the probe from the filament was necessary. This biasing

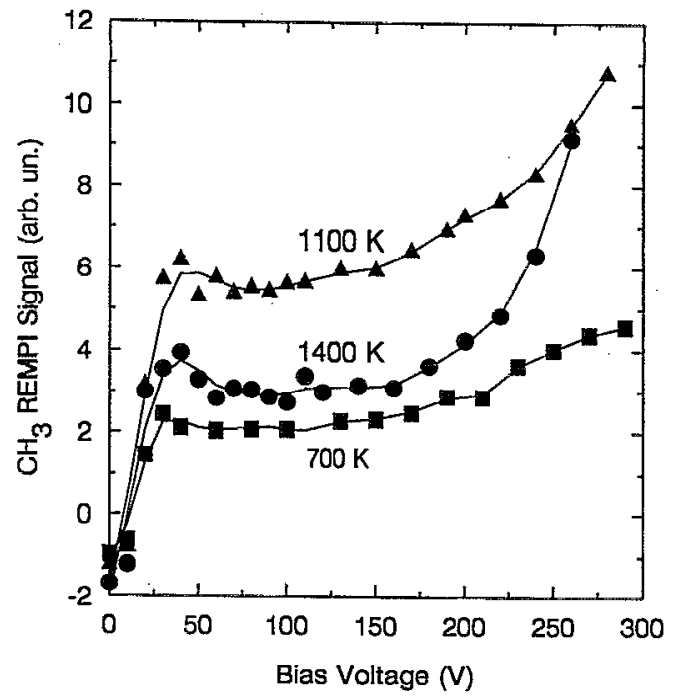

FIG. 3. Dependence of $\mathrm{CH}_{3}$ REMPI signal on probe bias voltage for three substrate temperatures.

scheme resulted in saturated electron collection for various experimental conditions, as evidenced by the plot of collected current vs bias voltage shown in Fig. 3. For the measurements discussed below, the probe bias voltage was set at $100 \mathrm{~V}$.

To verify the relationship of the REMPI signal to the concentration of the probed species near the surface, a small amount of argon was bled into the reactor and the $(3+1)$ REMPI signal at $314.4 \mathrm{~nm}$ from the Ar $3 p^{6}{ }^{1} S \rightarrow 3 p^{5} 4 s 4 s^{\prime}[1 / 2]^{\circ} J=1$ transition was measured as a function of filament and substrate temperatures, under the same conditions used for the $\mathrm{CH}_{3}$ REMPI measurements. Since argon is non-reactive, we expect the Ar concentration to vary inversely with gas temperature, due to the change in gas density with temperature. A similar procedure has been used previously by Smyth and Tjossem ${ }^{26}$ to calibrate the REMPI collection efficiency in flame experiments.

Since the $4 s^{\prime}$ transition is dipole-allowed, retroreflection of the beam to form a standing wave geometry is necessary to avoid cancellation of the REMPI signal by competing third harmonic generation. ${ }^{27}$ This was accomplished using two $20 \mathrm{~mm}$ focal length lenses and one mirror. Due to the sensitivity of the Ar ( $3+1)$ REMPI signal to the precise overlap of the beams at the focus, as well as to the stronger dependence of the signal on laser pulse energy (which was stable only to $5 \%$ ), the fluctuation in the Ar $(3+1)$ REMPI signal is larger than that we observed for the methyl $(2+1)$ signal. Nevertheless, the $\mathrm{Ar}$ REMPI signal shows the expected $1 / T$ dependence on substrate temperature to within experimental error, as seen in Fig. 4.

Since the $\mathrm{CH}_{3}$ REMPI signal results from the $v=0$ vibrational ground state, it measures directly only the population in this state. To relate this to the total $\mathrm{CH}_{3}$ population, we assume

$$
\left[\mathrm{CH}_{3}\right] \propto S Q_{\mathrm{vib}}(T),
$$




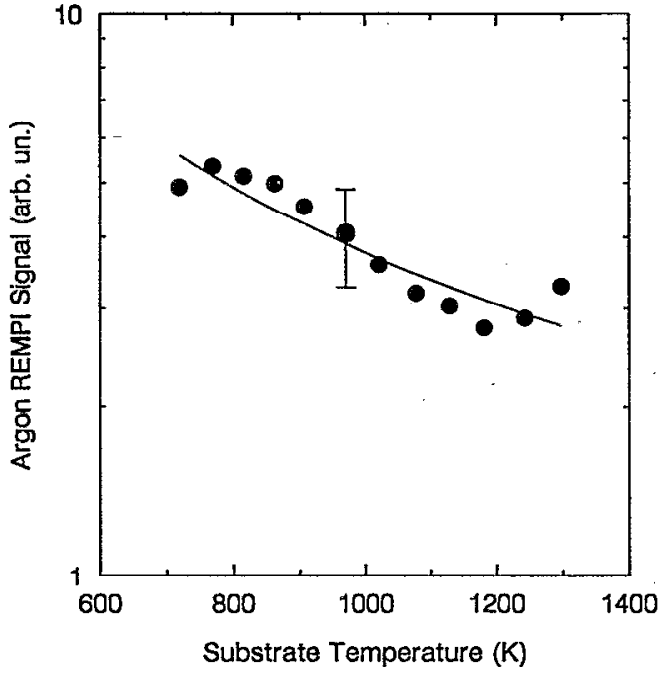

FIG. 4. Dependence of the Ar $4 s^{\prime}(3+1)$ REMPI signal on substrate temperature. The dashed curve shows a fit to a $T^{-1}$ variation expected due to ideal gas expansion.

where $S$ is the measured REMPI signal, $Q_{\text {vib }}$ is the vibrational partition function, and $T$ is the gas temperature at the measurement location. This temperature is not measured, but since the gas temperature must equal the substrate temperature at the substrate, we cstimate that it is within $50 \mathrm{~K}$ of the substrate temperature at the measurement location. We therefore evaluate Eq. (1) using the substrate temperature; the resulting error in $Q_{\text {vib }}$ is well within the experimental uncertainty.

The partition function is calculated from the known frequencies and degeneracies of the vibrational modes of $\mathrm{CH}_{3}\left(v_{1}=2992.6 \mathrm{~cm}^{-1}, v_{2}=606 \mathrm{~cm}^{-1}, v_{3}=3158.9\right.$ $\left.\mathrm{cm}^{-1}, v_{4}=1394.6 \mathrm{~cm}^{-1}, g_{1}=g_{2}=1, g_{3}=g_{4}=2\right)$, using measured and calculated vibrational energy levels for the first 5 levels of the $v_{2}$ mode ${ }^{28,29}$ and the harmonic oscillator approximation otherwise. Over the temperature range of interest here $(700-1300 \mathrm{~K}), Q_{\text {vib }}$ varies from 1.5 to 3.4 , resulting in more than a factor of 2 correction in the temperature dependence data. The large value of $Q_{\text {vib }}$ results primarily from the low-frequency out-of-plane vibrational mode $v_{2}$, which becomes significantly populated at these temperatures.

In principle, a similar partition function correction should be applied to the rotational levels as well, to account for the fact that the laser pumps only some rotational lines. However, this is not feasible in practice since the $Q$ branch is rotationally unresolved due to upper-state predissociation, and therefore the rotational lines are broad and overlapping. Instead, we assume, like previous investigators, ${ }^{30}$ that the unresolved rotational manifold of the $\mathrm{Q}$ branch is relatively temperature-independent. This assumption is plausible, since many rotational lines are simultaneously pumped. Further support for this approach is given by the spectra in Fig. 5, taken at substrate temperatures of $800 \mathrm{~K}$ and $1200 \mathrm{~K}$, which show no significant differences in the shape of the manifold. In this case, the

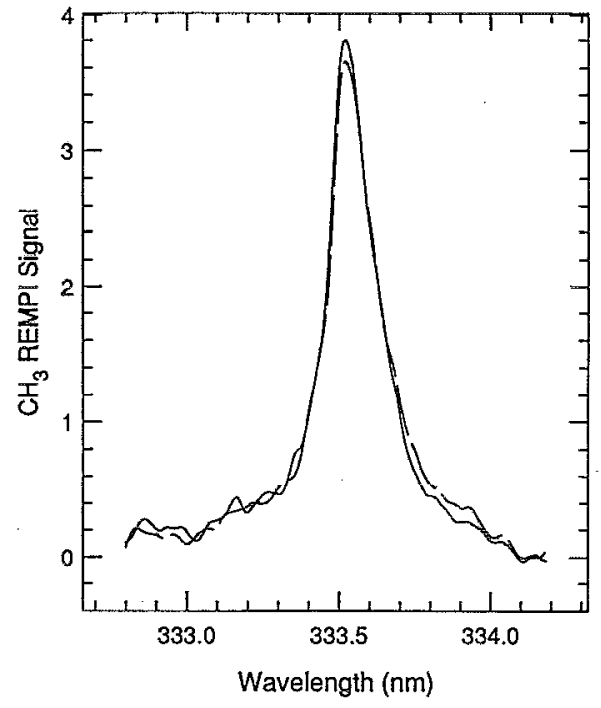

FIG. 5. Rotational manifold of the $\mathrm{CH}_{3}$ REMPI $\mathrm{Q}$ branch. The solid curve shows the measured profile at a substrate temperature of $800 \mathrm{~K}$, and the dashed curve shows the profile at $1200 \mathrm{~K}$. Both curves are normalized to equal area, and some smoothing has been done to allow a better comparison between the curves.

signal at the peak (where the concentration measurements are made) is proportional to the area under the curve to within experimental error. However, we cannot at present rule out the possibility that the appearance of the manifold is affected by $J$-dependent predissociation. In this case, there may be some temperature dependence to the REMPI signal which we do not account for here.

\section{RESULTS}

\section{A. Filament temperature dependence}

While the focus of this work is the effect of substrate temperature on species concentrations, some measurements of the filament temperature dependence were also made. The variations with filament temperature of the $\mathrm{CH}_{3}$ REMPI signal and the $\mathrm{CH}_{4}$ and $\mathrm{C}_{2} \mathrm{H}_{2}$ mole fractions near the substrate are shown in Fig. 6, for an initial gas composition of $0.5 \% \mathrm{CH}_{4}$ in $\mathrm{H}_{2}$. All measurements were performed with the substrate temperature fixed at $1000 \mathrm{~K}$. The conversion of methane to acetylene increases sharply above a filament brightness temperature of $2100 \mathrm{~K}$, accompanied by a sharp increase in the methyl REMPI signal. The $\mathrm{CH}_{4}$ and $\mathrm{C}_{2} \mathrm{H}_{2}$ results are similar to those reported previously for a gas composition of $3 \% \mathrm{CH}_{4}$ in $\mathrm{H}_{2} \cdot{ }^{24}$ Also, Celii and Butler ${ }^{23}$ report a similar variation of $\mathrm{CH}_{3}$ with filament temperature. The present results show conclusively that the sharp changes seen in $\mathrm{CH}_{4}, \mathrm{C}_{2} \mathrm{H}_{2}$, and $\mathrm{CH}_{3}$ all occur over the same filament temperature range, and occur even for the more typical composition used for diamond growth of $0.5 \% \mathrm{CH}_{4}$ in $\mathrm{H}_{2}$.

Sommer and $\mathrm{Smith}^{24}$ have argued that the sharp change in gas composition as the filament temperature is increased results from filament poisoning at low temperatures, due to a graphite layer coating the filament. For a 


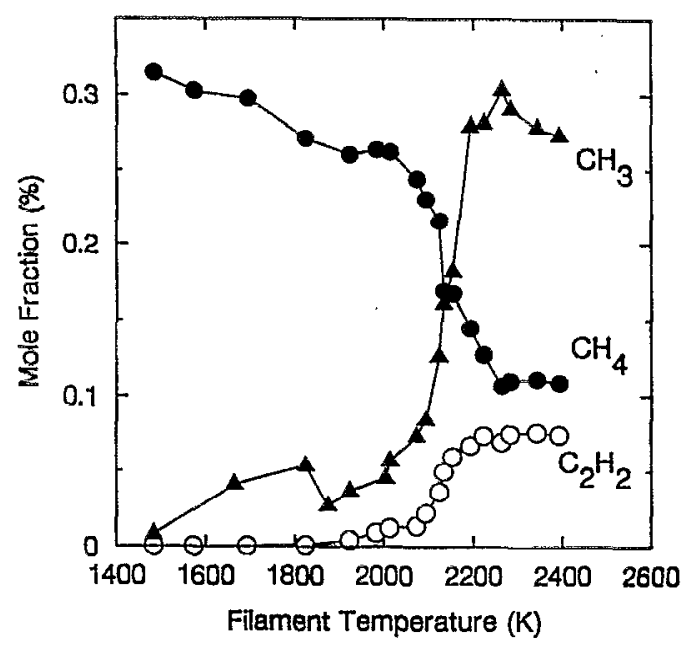

FIG. 6. Measured $\mathrm{CH}_{3}$ REMPI signal (arbitrary units) and $\mathrm{CH}_{4}$ and $\mathrm{C}_{2} \mathrm{H}_{2}$ mole fractions vs filament brightness temperature for $0.5 \% \mathrm{CH}_{4}$ in $\mathrm{H}_{2}, p=35 \mathrm{mbar}$, and $T_{s}=1000 \mathrm{~K}$.

composition of $0.5 \% \mathrm{CH}_{4}$ in $\mathrm{H}_{2}$, the carbon-hydrogen equilibrium phase diagram shows that graphite is stable below about $2170 \mathrm{~K},{ }^{24}$ and our measurements are consistent with this interpretation. (The actual filament temperature is somewhat higher than the brightness temperature, but when the filament is graphite-coated the emissivity is approximately 0.9 , so the difference is not large.)

As shown in Fig. 6, once the graphite layer desorbs from the filament, the $\mathrm{CH}_{3}, \mathrm{CH}_{4}$, and $\mathrm{C}_{2} \mathrm{H}_{2}$ signals saturate, and are apparently unaffected by further increases in filament temperature. This is in contrast to atomic hydrogen, which several studies have shown to continue to increase with increasing filament temperature. ${ }^{31-33}$

The effect of gas flow rate on the methane and acetylene mole fractions is shown in Fig. 7. While the $\mathrm{CH}_{4}$ mole fraction in the exhaust gas was measured to be $0.5 \%$ at low

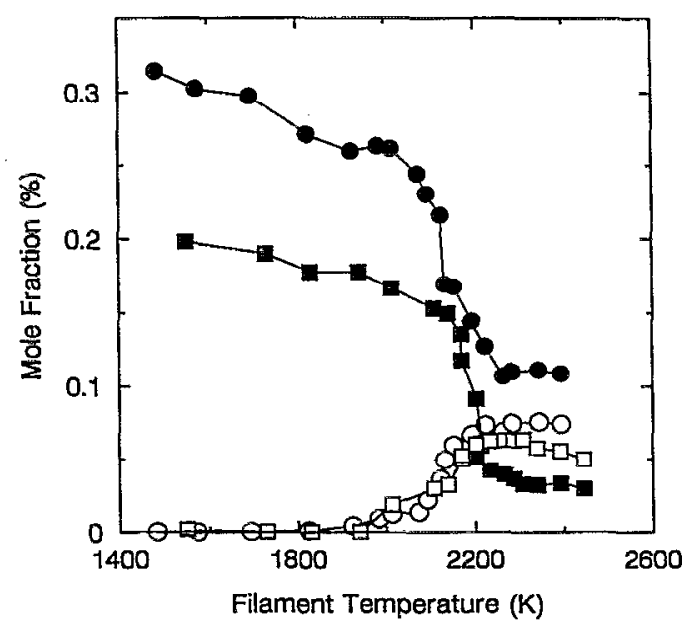

FIG. 7. Methane and acetylene mole fractions vs filament temperature for two different gas flow rates. Solid symbols: $\mathrm{CH}_{4}$ mole fraction; open symbols: $\mathrm{C}_{2} \mathrm{H}_{2}$ mole fraction; squares: $100 \mathrm{sccm}$; circles: $400 \mathrm{sccm}$.

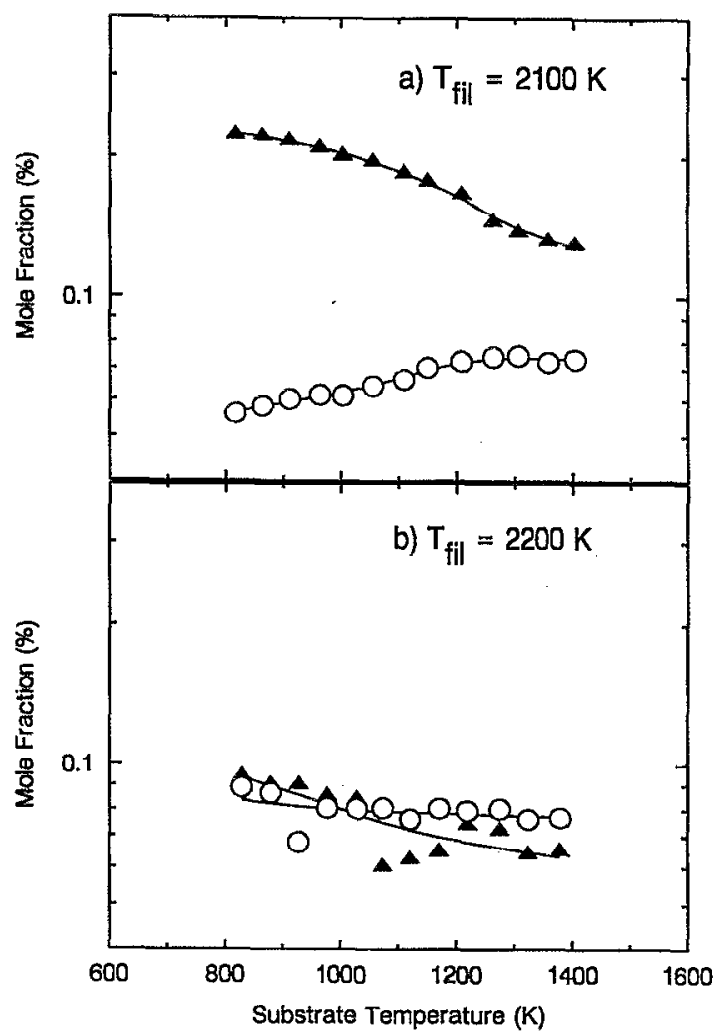

FIG. 8. Substrate temperature dependence of $\mathrm{CH}_{4}$ and $\mathrm{C}_{2} \mathrm{H}_{2}{ }^{-}$. (a) $T_{\mathrm{fil}}$ $=2100 \mathrm{~K}$; (b) $T_{\text {fil }}=2200 \mathrm{~K}$. Circles: $\mathrm{C}_{2} \mathrm{H}_{2}$; triangles: $\mathrm{CH}_{4}$.

filament temperatures, near the substrate it is always less than this value, and shows a dependence on gas flow rate. This behavior is consistent with thermal diffusion (the Soret effect), which will cause heavy species to diffuse preferentially to cold regions of the reactor near the walls, depleting the hot filament/substrate region of hydrocarbons. The conversion of methane to acetylene is seen to be relatively unaffected by gas flow rate, since for both cases the change in the $\mathrm{CH}_{4}$ signal and the magnitude of the $\mathrm{C}_{2} \mathrm{H}_{2}$ signal are nearly the same.

\section{B. Substrate temperature dependence}

The substrate temperature dependence of the $\mathrm{CH}_{4}$ and $\mathrm{C}_{2} \mathrm{H}_{2}$ mole fractions is shown in Fig. 8. At $T_{\text {fil }}=2100 \mathrm{~K}$ (where the filament is still partially graphite-coated and $\mathrm{CH}_{4}$ concentrations are still high) some conversion of methane to acetylene occurs as the substrate temperature is raised; this may, however, be due to an increase in the average gas temperature, rather than direct conversion on the substrate. (The possibility that increasing the substrate temperature could affect the filament temperature was examined by monitoring the filament power, voltage drop, and brightness temperature. Since these were found to be independent of substrate temperature, we conclude that the conversion of methane to acetylene is not due to a slight increase in the filament temperature.) At $T_{\mathrm{fil}}=2200 \mathrm{~K}$, where the graphite layer has largely been removed from the 


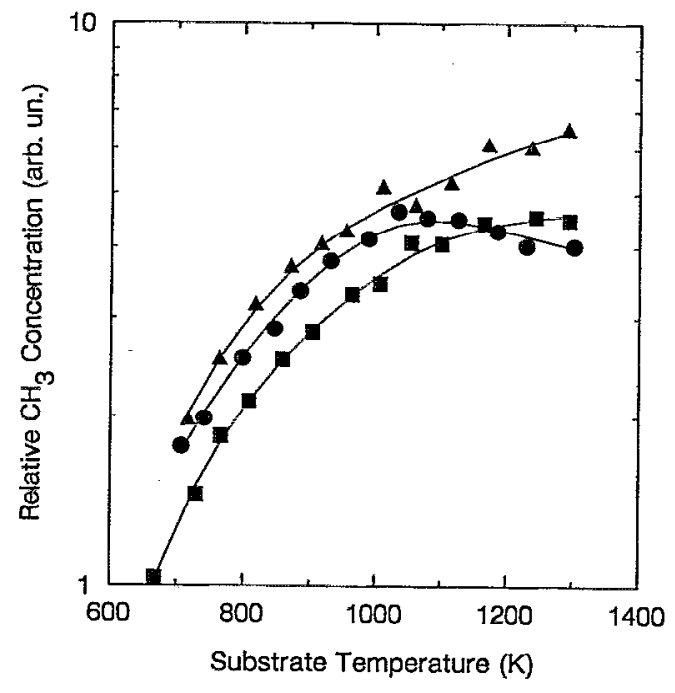

FIG. 9. Dependence of the $\mathrm{CH}_{3}$ relative concentration on substrate temperature. Triangles: $T_{\mathrm{fil}}=2200 \mathrm{~K}, 400 \mathrm{sccm}$; circles: $T_{\mathrm{fl}}=2200 \mathrm{~K}, 100$ sccm; squares: $T_{\text {fil }}=2100 \mathrm{~K}, 400 \mathrm{sccm}$.

filament, no effect of substrate temperature on acetylene is seen, and only a small decrease in the methane mole fraction is observed.

The substrate temperature has a larger effect on the near-substrate methyl radical concentration, however, as indicated in Fig. 9. The relative $\mathrm{CH}_{3}$ concentration near the substrate is shown as a function of substrate temperature for two different flow rates (100 sccm and $400 \mathrm{sccm}$ ) and filament temperatures $(2100 \mathrm{~K}$ and $2200 \mathrm{~K})$. In each case, the methyl concentration rises as the substrate temperature is increased from 700 to $1000 \mathrm{~K}$, then increases more slowly or begins to decrease at higher substrate temperatures. The change in the $\mathrm{CH}_{3}$ REMPI signal observed for increasing substrate temperature was completely reversible when the substrate temperature was lowered, and was very repeatable from run to run. Also, the results do not appear to be reactor-specific, since we found the same behavior in REMPI measurements carried out in a muchlarger bell jar reactor as in the small 5-way cross.

The substrate temperature dependence of the $\mathrm{CH}_{3}$ signal measured near the substrate is compared in Fig. 10 with the signal observed $4 \mathrm{~mm}$ above the substrate. Since the gas temperature away from the substrate is not measured, no partition function correction could be applied to this data, and therefore the uncorrected REMPI signals at the two locations are compared in this figure. These results indicate that the fall-off in methyl seen near the substrate at low temperatures is not observed further away. We therefore conclude that it is due to chemistry occurring in the gas phase in the immediate vicinity of the substrate, or else directly on the surface.

An Arrhenius plot of the data of Fig. 9 is shown in Fig. 11. At temperatures below about $1000 \mathrm{~K}$, the data fall on reasonably straight lines, and can all be described by an activation energy of approximately $4 \mathrm{kcal} / \mathrm{mole}$. We may compare this value to reported activation energies for the

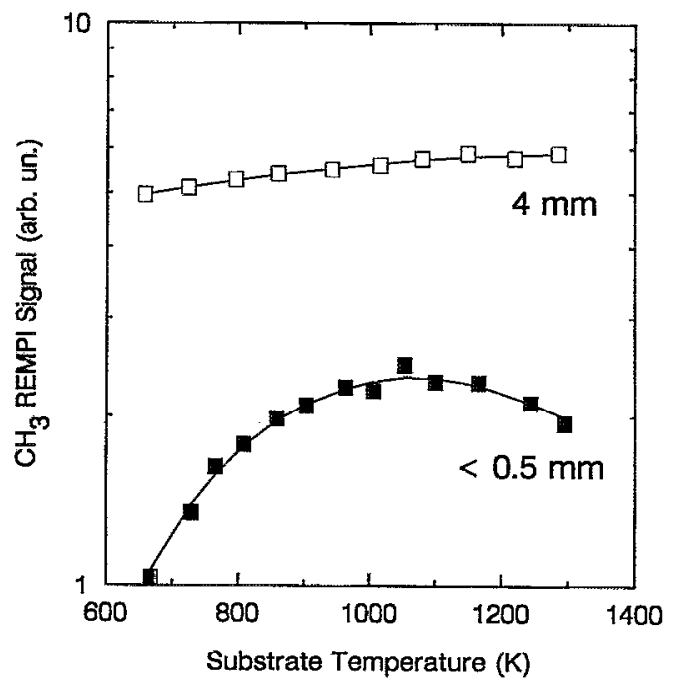

FIG. 10. Comparison of uncorrected REMPI signal vs substrate temperature just above substrate to that $4 \mathrm{~mm}$ away.

diamond growth rate. Kondoh et al. ${ }^{16}$ have measured growth rates which peak at about $1200 \mathrm{~K}$, and decline for higher temperatures. They report an activation energy in the temperature range of $1000-1200 \mathrm{~K}$ of $22-24 \mathrm{kcal} /$ mole. Chu et al. ${ }^{17}$ have measured the homoepitaxial growth rates on (100), (111), and (110) faces over the temperature range of 950-1250 K. They report activation energies of 8,12 , and $18 \mathrm{kcal} / \mathrm{mole}$ for homoepitaxial growth on the (100), (111), and (110) faces, respectively, although the temperature dependence appears to be larger in the range $950-1000 \mathrm{~K}$, and they assign an activation energy of $50 \mathrm{kcal} / \mathrm{mole}$ in this region. This comparison indicates that the temperature dependence of the methyl

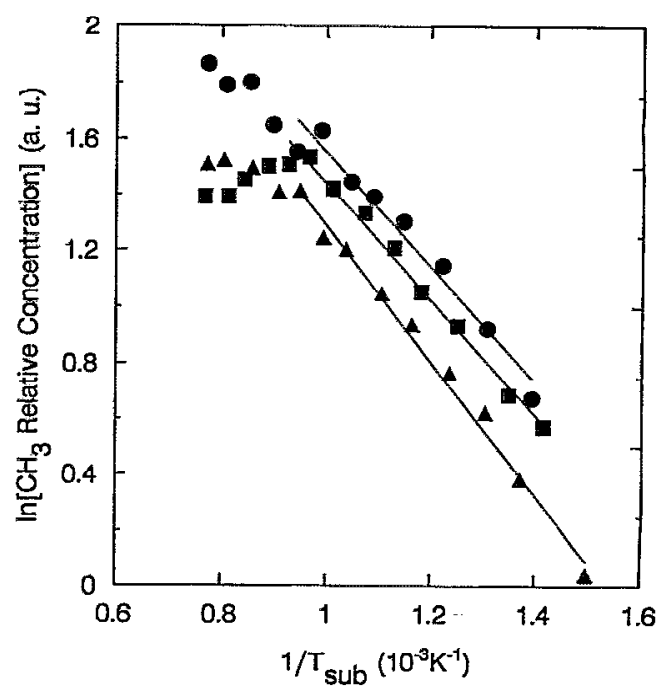

FIG. 11. Arrhenius plot of data in Fig. 9. The low temperature fall-off of $\mathrm{CH}_{3}$ may be characterized by an activation energy of approximately 4 $\mathrm{kcal} / \mathrm{mole}$. 


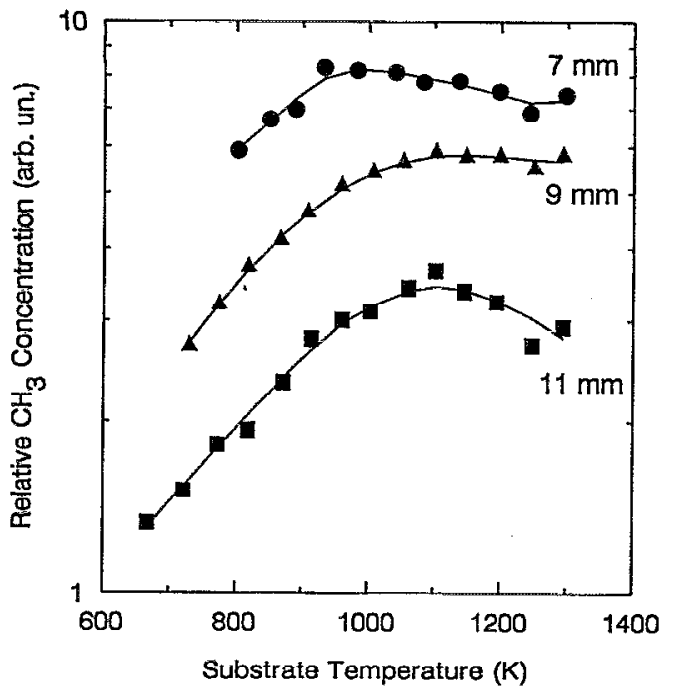

FIG. 12. Relative $\mathrm{CH}_{3}$ concentration at the substrate vs substrate temperature for three different substrate to filament distances.

radical concentration at the surface contributes to the measured activation energies for growth, but is less important than other factors.

A similar dependence of the $\mathrm{CH}_{3}$ concentration on substrate temperature is observed for different filamentsubstrate separations, as seen in Fig. 12. In all cases, the rise with temperature is approximately the same below $1000 \mathrm{~K}$, and a saturation or decline is seen above $1000 \mathrm{~K}$. The larger absolute signal at $7 \mathrm{~mm}$ compared to $11 \mathrm{~mm}$ indicates a larger $\mathrm{CH}_{3}$ concentration closer to the filament, in agreement with expectation and previous measurements, ${ }^{23}$ although variations in REMPI collection efficiency with filament-substrate distance may affect the relative magnitude of the signal at the three distances.

The effect of different gas compositions on the $\mathrm{CH}_{3}$ temperature dependence is shown in Fig. 13. At low temperatures, the rate of increase of $\mathrm{CH}_{3}$ is very similar for the three compositions shown here. However, there is a pronounced shift in the location of the peak of the $\mathrm{CH}_{3}$ concentration as the hydrocarbon content of the gas increases. For the $5 \%$ case, $\mathrm{CH}_{3}$ declines at higher substrate temperatures. The methyl concentration is also seen to be approximately proportional to the initial methane fraction. As the $\mathrm{CH}_{4}$ fraction is increased to $1 \%$ from $0.5 \%$, the measured $\mathrm{CH}_{3}$ concentration increases by about a factor of two below $1000 \mathrm{~K}$, but somewhat less than this at higher temperatures.

\section{DISCUSSION}

The methyl concentration at the surface is determined both by chemistry, which may occur either in the gasphase near the substrate or on the surface, and transport from further away in the gas. To properly interpret this data requires a numerical simulation which can account for all of these effects. A detailed comparison of this data

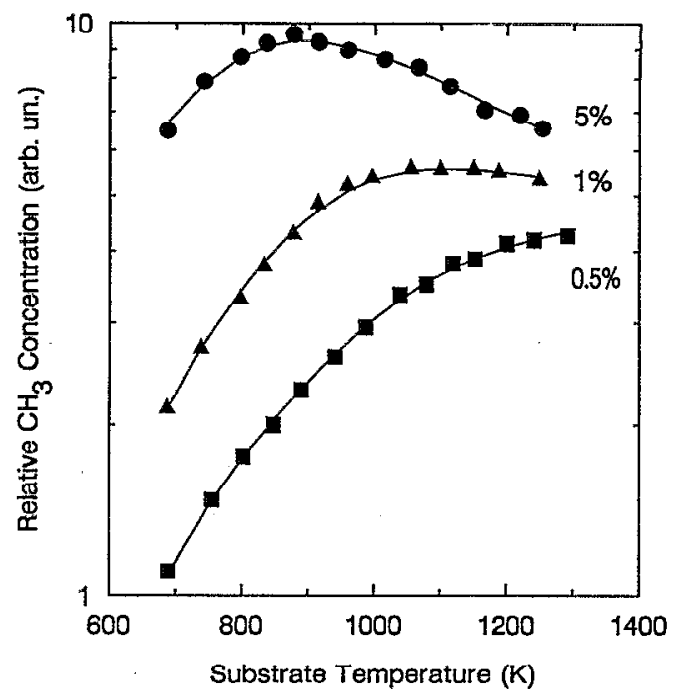

FIG. 13. Relative $\mathrm{CH}_{3}$ concentration at the substrate vs substrate temperature for three different methane percentages in the initial gas mixture. The $5 \%$ curve has been scaled to fit on the same plot.

with model predictions will be presented elsewhere. Here we only indicate the most likely factors influencing the methyl concentration at the substrate.

Modeling studies ${ }^{18,19}$ have shown that away from the substrate the methyl concentration under typical filamentassisted conditions is set by the partial equilibrium of the rapid reaction

$$
\mathrm{CH}_{4}+\mathrm{H} \rightleftharpoons \mathrm{CH}_{3}+\mathrm{H}_{2} \text {. }
$$

The equilibrium constant for this reaction is nearly independent of temperature. Thus, if this reaction controls the $\mathrm{CH}_{3}$ concentration, we have that $\left[\mathrm{CH}_{3}\right] \propto\left[\mathrm{CH}_{4}\right][\mathrm{H}] /\left[\mathrm{H}_{2}\right]$.

The observed results could be explained if reaction (2) is in partial equilibrium near the substrate and the atomic hydrogen concentration decreases at low temperatures. However, both simulations ${ }^{19}$ and measurements ${ }^{34}$ show that the partial equilibrium of reaction (2) breaks down near the surface. Also, the atomic hydrogen concentration at the surface is governed by a balance between diffusion to the surface and surface recombination; a lower $\mathrm{H}$ concentration at low substrate temperatures would require that the surface recombination coefficient of $\mathrm{H}$ on diamond be larger at low temperatures than at high temperatures. However, recent measurements ${ }^{35,36}$ show that the recombination coefficient increases with temperature, as it does on similar surfaces, such as quartz and glass. . $^{37,38}$

A second type of gas-phase reaction which might account for the present results is a radical-radical recombination reaction, such as

$$
\mathrm{CH}_{3}+\mathrm{CH}_{3} \rightarrow \mathrm{C}_{2} \mathrm{H}_{6}
$$

or

$$
\mathrm{CH}_{3}+\mathrm{H} \rightarrow \mathrm{CH}_{4} \text {. }
$$

Both of these reactions have pressure-dependent rate constants with negative temperature exponents (faster at 
lower temperature) ${ }^{39,40}$ Using rate constants appropriate for $35 \mathrm{mbar}$ and estimated mole fractions based on the measurements of $\mathrm{Hsu}^{41}$ for a similar filament-assisted experiment, we find that these two reactions contribute almost equally to methyl consumption in this temperature range. We estimate that the methyl destruction time, considering both reactions, is $200 \mu$ s at $700 \mathrm{~K}$, while at $1400 \mathrm{~K}$ it is an order of magnitude longer $(2 \mathrm{~ms})$. An additional factor may be that reaction (2) has an activation energy of almost $9 \mathrm{kcal} / \mathrm{mole}^{39}$ and therefore cannot replenish methyl lost by (3) or (4) as rapidly at lower temperatures.

It is also possible that $\mathrm{CH}_{3}$ could recombine heterogeneously on the diamond surface. Also, methyl is known to be a primary etch product of $\mathrm{H}$-attack on amorphous carbon. ${ }^{42,43}$ Etching of non-diamond carbon by atomic hydrogen is widely thought to be an essential aspect of CVD diamond growth, resulting in suppression of non-diamond phases. Since etching of carbon films by atomic hydrogen typically has a small positive activation energy (e.g., $5.3 \pm 1.9 \mathrm{kcal} / \mathrm{mole}^{44}$ ), if this process occurs rapidly enough it could result in production of methyl at higher temperatures, leading to a temperature dependence similar to that observed here. We are currently carrying out detailed modeling studies, incorporating diffusion, gas-phase chemistry, and surface chemistry, to assess the relative importance of these mechanisms.

\section{SUMMARY}

The filament- and substrate-temperature dependence of the $\mathrm{CH}_{3}, \mathrm{CH}_{4}$, and $\mathrm{C}_{2} \mathrm{H}_{2}$ concentrations near the substrate during filament-assisted diamond growth has been determined. The dependence on filament temperature is consistent with previous studies, and clearly shows that a reduction in filament activity at low temperatures occurs even for the dilute $0.5 \% \mathrm{CH}_{4}$ in $\mathrm{H}_{2}$ gas composition. The substrate temperature studies show that $\mathrm{CH}_{4}$ and $\mathrm{C}_{2} \mathrm{H}_{2}$ are relatively independent of substrate temperature at sufficiently high filament temperatures. On the other hand, $\mathrm{CH}_{3}$ near the substrate exhibits a distinct temperature dependence which is qualitatively similar for all gas compositions, filament-substrate separations, flow rates, and filament temperatures. The most likely explanation for this behavior is recombination of $\mathrm{CH}_{3}$ to $\mathrm{CH}_{4}$ or $\mathrm{C}_{2} \mathrm{H}_{6}$ at low substrate temperatures, either through homogeneous chemistry occurring near the substrate, or heterogeneous chemistry on the substrate. These results suggest that depletion of growth species due to recombination may need to be considered in designing low-temperature processes for CVD diamond growth.

\section{ACKNOWLEDGMENTS}

We would like to thank Dr. Jay Jeffries (SRI), Dr. Steve Harris (General Motors), Professor Terry Cool (Cornell), and Dr. U. Meier (DLR) for useful discussions regarding the REMPI measurements. This work is supported, in part, by the Office of Naval Research, under contract N00014-90-J-1386, with an additional equipment grant from the AT\&T Foundation. One of us (EJC) grate- fully acknowledges support from the Conselho Nacional de Desenvolvimento Científico e Tecnológico, Brazil.

${ }^{1}$ C. J. Chu, M. P. D'Evelyn, R. H. Hauge, and J. L. Margrave, J. Mater. Res. 5, 2405 (1990).

${ }^{2}$ C. J. Chu, M. P. D'Evelyn, R. H. Hauge, and J. L. Margrave, J. Appl. Phys. 70, 1695 (1991).

${ }^{3}$ S. J. Harris and A. M. Weiner, J. Appl. Phys. 70, 1385 (1991).

${ }^{4}$ S. J. Harris and L. R. Martin, J. Mater. Res. 5, 2313 (1990).

${ }^{5}$ L. R. Martin and M. W. Hill, J. Mater. Sci. Lett. 9, 621 (1990).

${ }^{6}$ G. A. Raiche, G. P. Smith, and J. B. Jeffries, Proceedings of the International Conference on Diamond and Science Technology, edited by $\mathbf{R}$. Messier, J. T. Glass, J. E. Butler, and R. Roy (Materials Research Society, Pittsburgh, PA, 1991), pp. 251-256.

${ }^{7}$ D. G. Goodwin, Appl. Phys. Lett. 59, 277 (1991).

${ }^{8}$ M. Tsuda, M. Nakajima, and S. Oikawa, J. Am. Chem. Soc. 108, 5780 (1986).

${ }^{9}$ S. J. Harris, Appl. Phys. Lett. 56, 2298 (1990).

${ }^{10}$ S. J. Harris and D. N. Belton, Thin Solid Films 212, 193 (1992).

${ }^{11}$ B. J. Garrison, E. J. Dawnkaski, D. Srivastava, and D. W. Brenner, Science 255, 835 (1992).

${ }^{12}$ D. Huang and M. Frenklach, J. Phys. Chem. 96, 1868 (1992).

${ }^{13}$ M. Frenklach and K. E. Spear, J. Mater. Res. 3, 133 (1991).

${ }^{14}$ D. Huang, M. Frenklach, and M. Maroncelli, J. Phys. Chem. 92, 6379 (1988).

${ }^{15}$ D. N. Belton and S. J. Harris, J. Chem. Phys. 96, 2371 (1992).

${ }^{16}$ E. Kondoh, T. Ohta, T. Mitomo, and K. Ohtsuka, Appl. Phys. Lett. 59, 488 (1991).

${ }^{17}$ C. J. Chu, R. H. Hauge, J. L. Margrave, and M. P. D'Evelyn, Appl. Phys. Lett. 61, 1393 (1992).

${ }^{18}$ D. G. Goodwin and G. G. Gavillet, J. Appl. Phys. 68, 6393 (1990).

${ }^{19}$ D. G. Goodwin and G. G. Gavillet, Proceedings of the International Conference on New Diamond Science and Technology, edited by $\mathrm{R}$. Messier, J. T. Glass, J. E. Butler, and R. Roy (Materials Research Society, Pittsburgh, PA, 1991), pp. 335-340.

${ }^{20}$ Y. Matsui, H. Yabe, and Y. Hirose, Jpn. J. Appl. Phys. 29, 1552 (1990).

${ }^{21}$ J. S. Kim and M. A. Cappelli, "A Model of Diamond Growth in Low Pressure Premixed Flames," Western States Section, The Combustion Institute, 1992 Spring Meeting.

${ }^{22}$ E. Meeks, R. J. Kee, M. E. Coltrin, and D. S. Dandy, "Computational Simulation of Diamond Chemical Vapor Deposition in Premixed $\mathrm{C}_{2} \mathrm{H}_{2} / \mathrm{O}_{2} / \mathrm{H}_{2}$ and $\mathrm{CH}_{4} / \mathrm{O}_{2}$ Strained Flames," Western States Section, The Combustion Institute, 1992 Spring Meeting.

${ }^{23}$ F. G. Celii and J. E. Butler, J. Appl. Phys. 71, 2877 (1992).

${ }^{24}$ M. Sommer and F. W. Smith, J. Mater. Res. 5, 2433 (1990).

${ }^{25}$ S. J. Harris, A. M. Weiner, and T. A. Perry, Appl. Phys. Lett. 53, 1605 (1988).

${ }^{26}$ K. C. Smyth and P. J. H. Tjossem, Appl. Opt. 29, 4891 (1990).

${ }^{27}$ L. Li, M. Wu, and P. M. Johnson, J. Chem. Phys. 89, 3470 (1988).

${ }^{28}$ V. Spirko and P. R. Bunker, J. Mol. Spectrosc. 95, 381 (1982).

${ }^{29}$ C. Yamada, E. Hirota, and K. Kawaguchi, J. Chem. Phys. 75, 5256 (1981).

${ }^{30}$ J. S. Bernstein, A. Fein, J. B. Choi, T. A. Cool, R. C. Sausa, S. L. Howard, R. J. Locke, and A. W. Miziolek, Combustion and Flame 92, 85 (1993).

${ }^{31}$ F. G. Celii and J. E. Butler, Appl. Phys. Lett. 54, 1031 (1989).

${ }^{32}$ K. H. Chen, M. C. Chuang, C. M. Penney, and W. F. Banholzer, J. Appl. Phys. 71, 1485 (1992).

${ }^{33}$ W. L. Hsu, Proceedings of the International Symposium on Diamond and Related Materials, edited by A. J. Purdes, K. E. Spear, B. S. Meyerson, M. Yoder, R. Davis, and J. C. Angus (The Electrochemical Society, Pennington, NJ, 1991), pp. 217-223.

${ }^{34}$ W. L. Hsu, Appl. Phys. Lett. 59, 1427 (1991).

${ }^{35}$ S. J. Harris and A. M. Weiner, J. Appl. Phys. 74, 1022 (1993).

${ }^{36} \mathrm{~J}$. A. Proudfit and M. A. Cappelli, Proceedings of the International Symposium on Diamond Materials, edited by A. J. Purdes, K. E. Spear, B. S. Meyerson, M. Yoder, R. Davis, and J. C. Angus (The Electrochemical Society, Pennington, NJ, in press).

${ }^{37}$ W. V. Smith, J. Chem. Phys. 11, 110 (1943).

${ }^{38}$ M. Green, K. R. Jennings, J. W. Linnett, and D. Schofield, Trans. Faraday Soc. 55, 2152 (1959). 
${ }^{39} \mathrm{~J}$. Warnatz, in Combustion Chemistry, edited by W. C. Gardiner, Jr. (Springer, New York, 1984), p. 197.

${ }^{40}$ C. J. Cobos and J. Troe, Zeitsch. Phys. Chem. Neue Folge 167, 129 (1990).

${ }^{41}$ W. L. Hsu, J. Appl. Phys. 72, 3102 (1992).
${ }^{42}$ W. L. Hsu, J. Vac. Sci. Technol. A 6, 1803 (1988).

${ }^{43}$ E. Vietzke, K. Flaskamp, V. Philipps, G. Esser, P. Wienhold, and J. Winter, J. Nucl. Mater. 145-147, 443 (1987).

${ }^{44}$ R. R. Rye, Surf. Sci. 69, 653 (1977). 